\title{
Stereotactic large core needle biopsy for all nonpalpable breast lesions?
}

\author{
L.E. Hoorntje ${ }^{1}$, P.H.M. Peeters ${ }^{2}$, I.H.M. Borel Rinkes ${ }^{1}$, H.M. Verkooijen ${ }^{4}$, R.M. Pijnappel ${ }^{5}$, and \\ W.P.Th.M. Mali ${ }^{3}$ \\ ${ }^{1}$ Department of Surgery, ${ }^{2}$ Julius Center for Patient Oriented Research, ${ }^{3}$ Department of Radiology, University \\ Medical Centre, Utrecht, The Netherlands; ${ }^{4}$ Registre Genevois des Tumeurs, Institut de Médecine Sociale et \\ Préventive, Université de Genève, Genève, Switzerland; ${ }^{5}$ Department of Radiology, Martini Hospital Groningen, \\ Groningen, The Netherlands
}

Key words: breast cancer, large core needle biopsy, nonpalpable, screening

\section{Summary}

Background. Stereotactic large-core needle biopsy (SLCNB) is a minimally invasive method for histological diagnosis of nonpalpable breast disease. We studied differences in cancer prevalence between a group of women referred through the national screening program and a non-screening group, and assessed whether the validity of SLCNB differed between these groups.

Methods. A group of non-selective, consecutive patients presenting with a nonpalpable mammographic lesion, who participated in a recently conducted multicenter study regarding the accuracy of SLCNB in The Netherlands, were the basis for this study. Prevalence of carcinoma, predictive value of a benign diagnosis, sensitivity, and specificity rate of SLCNB were compared between the two groups.

Results. Of the 1029 lesions in 972 patients included, 858 were evaluable. In 850/858 lesions (99.1\%) the reason for referral was clear. The prevalence of cancer in the screening group ( $n=511$ lesions) was $64.0 \%$ (95\%CI 59.8-68.2), versus $49.6 \%$ in the non-screening group ( $n=339$ ) (95\% CI 44.2-54.9). Respective predictive values of a benign diagnosis on SLCNB were 97.0 versus $94.8 \%$ (non-significant). The sensitivity rates of SLCNB were $98.5 \%$ (screening; 95\% CI 96.5-99.5) versus 95.2\% (non-screening; 95\% CI 90.8-97.9). Specificity rates were 97.8 (95\% CI 94.5-99.4) and 99.4\% (95\%CI 96.8-100), respectively.

Conclusion. Despite a significant difference in the prevalence of carcinoma, the accuracy of SLCNB did not show a statistically significant difference between both patient groups. Therefore, SLCNB appears accurate in diagnosing nonpalpable breast lesions both in screening and non-screening patient groups.

\section{Introduction}

The national breast cancer screening program is designed to screen asymptomatic women to detect malignancies at an earlier, nonpalpable stage, in order to reduce breast-cancer associated morbidity and mortality [1-5]. In The Netherlands, all women aged 50-70 (and since 1998, 50-75) years are invited to participate $[6,7]$. Essential in the concept of screening is that all women participating are by definition asymptomatic.

Since most of the discovered mammographic abnormalities are nonpalpable, confirmation of the diagnosis is a challenge for the surgeon these women are referred to. Diagnostic wire-localised open breast biopsy has long been the reference test for nonpalpable breast disease. However, in the last decade, various minimally invasive diagnostic procedures have been developed [8-10]. Recently, we have tested the stereotactic large core needle biopsy (SLCNB) in a Dutch prospective multicenter trial, the COBRA study (COre Biopsy after RAdiological localisation) [11]. In a group of 972 consecutive women with 1029 nonpalpable mammographic abnormalities SLCNB was performed to determine the histological diagnosis. In each patient, SLCNB was followed by surgical excision (wire localised excision biopsy for nonmalignant lesions, breast conserving treatment or mastectomy for malignant lesions) to compare the initial diagnosis with that of the gold standard. The sensitivity and specificity of the new technique were 97 and 99\%, 
respectively, and thus are comparable to surgical biopsy [11-13].

Sixty percent of women included in the COBRA cohort were referred by the national screening program. Consequently, $40 \%$ were women with some motive other than an age-induced screening invitation to have their mammogram taken, including a personal or family history of breast cancer, perceived changes in their breast or anxiety. The purpose of this study was to compare these two groups, different in background of referral, with regard to prevalence of cancer and possible consequences for the accuracy of SLCNB. Our hypothesis was that the prevalence of carcinoma would be higher in the screening group.

As has been described before, diagnostic test parameters vary across subpopulations within a certain population [14]. We compared the two groups (screening vs. non-screening) to evaluate if the results with SLCNB obtained in the COBRA study may be applied with equal validity to different subpopulations within the cohort of patients with nonpalpable breast lesions.

\section{Patients and methods}

\section{Study population}

Data was used from the COBRA study. The methods and results of this study are described elsewhere [11]. For the purpose of the present study we categorised the patients in two groups: one group referred by the national screening program ('screening', $n=511$ lesions) and one consisting of patients with a specific motive for mammographic surveillance ('non-screening', $n=339$ lesions). Demographic information, relevant medical history, breast cancer risk factors, mammographic findings, and histological factors were prospectively collected and compared between the two groups.

\section{Accuracy of large-core needle biopsy}

We evaluated the diagnostic accuracy of large-core needle biopsy using a methodology adapted from Burbank and Parker [15].

Histological diagnoses of the core biopsy specimens were divided into five categories: normal breast tissue (i.e., not explanatory for the mammographic lesion), benign breast disease, high-risk lesions, DCIS, and invasive breast cancer. Histological diagnoses of the surgical specimens were divided into the same categories.
High-risk lesions were those known to have a high prevalence of carcinoma on excision biopsy (atypical ductal hyperplasia (ductal or lobular) and lobular carcinoma in situ) [16-18]. In cases of such a high-risk diagnosis on large-core needle biopsy an open breast biopsy is generally recommended $[19,20]$.

Subsequently, the predictive value of a 'normal breast tissue' diagnosis, the predictive value of a 'benign' diagnosis, the high-risk underestimate rate and ductal carcinoma in situ (DCIS) underestimate rate as well as the sensitivity and specificity rates were calculated and compared between the subgroups.

The predictive value of a 'normal breast tissue' diagnosis was defined as the proportion of lesions diagnosed as 'normal' on large-core needle biopsy that did not reveal carcinoma (DCIS or invasive) at excision biopsy. Similarly, the predictive value of a 'benign' diagnosis was defined as the proportion of lesions with a benign diagnosis on large-core needle biopsy that proved to be benign after excision biopsy. The high-risk underestimate rate was defined as the proportion of lesions diagnosed as high-risk by largecore needle biopsy that was upgraded to DCIS or invasive cancer in the surgical specimen. The DCIS underestimate rate was defined as the proportion of lesions diagnosed as DCIS by large-core needle biopsy that was upgraded to invasive cancer in the surgical specimen.

The sensitivity rate was defined as the proportion of malignancies that was identified as abnormal (hence, warranting surgical excision) by SLCNB and the specificity rate was defined as the proportion of benign lesions that was not categorised as carcinoma (DCIS or invasive carcinoma) by SLCNB.

\section{Statistical analysis}

Statistical analysis was performed with use of the Statistical Package for the Social Sciences 7.5 (SPSS Inc. Chicago, IL). Continuous data were tested using the Student's $t$-test. Nominal data were tested by means of the Chi-square test.

\section{Results}

\section{Study population}

Between April 1997 and February 2000, 972 consecutive patients with 1029 nonpalpable mammographic lesions were included in the COBRA study. For 850 of the evaluable 858 lesions $(99 \%)$ the background 
Table 1. Patient- and lesion characteristics

\begin{tabular}{|c|c|c|c|}
\hline & $\begin{array}{l}\text { Screening } \\
n=511\end{array}$ & $\begin{array}{l}\text { Non-screening } \\
n=339\end{array}$ & $\begin{array}{l}\text { Total } \\
n=850\end{array}$ \\
\hline \multicolumn{4}{|l|}{ Risk factors } \\
\hline Age $\geq 50$ yrs $(\%)$ & $98.0^{* *}$ & 59.3 & 82.6 \\
\hline Mean age at menarche (yrs) & $13.4^{* *}$ & 13.2 & 13.3 \\
\hline Mean age at first full term pregnancy (yrs) & 25.5 & 26.1 & 25.7 \\
\hline Hormone replacement therapy use $(\%)$ & 45.6 & 54.5 & 49.1 \\
\hline History of breast cancer (\%) & 2.2 & $29.8^{* *}$ & 13.2 \\
\hline History of benign breast disease $(\%)$ & 16.8 & $28.9^{* *}$ & 21.6 \\
\hline Familiar history of breast cancer $(\%)$ & 26.5 & $37.9^{* *}$ & 30.9 \\
\hline Nullipara $(\%)$ & 14.7 & 23.1 & 18.0 \\
\hline BMI $\left(\mathrm{kg} / \mathrm{m}^{2}\right)($ mean$)$ & $26.0^{* *}$ & 24.9 & 25.6 \\
\hline \multicolumn{4}{|l|}{ Mammography } \\
\hline Density (\%) & $41.1^{* *}$ & 28.0 & 35.7 \\
\hline Microcalcifications (\%) & 39.9 & $57.2^{* *}$ & 46.7 \\
\hline Density with microcalcifications (\%) & 15.7 & 11.8 & 14.3 \\
\hline Distorded architecture $(\%)$ & 3.1 & 2.7 & 3.0 \\
\hline Focal asymmetry (\%) & 0.2 & 0.3 & 0.2 \\
\hline \multicolumn{4}{|l|}{ Radiological classification* } \\
\hline Probably benign (\%) & 26.7 & 38.0 & 31.3 \\
\hline Suspicious for malignancy (\%) & 51.4 & 49.0 & 50.2 \\
\hline Malignant $(\%)$ & $21.9^{* *}$ & 13.0 & 18.4 \\
\hline
\end{tabular}

* Radiological classification registered by radiologist performing the SLCNB.

** Significantly different between screening and non-screening with a $p$-value of $<0.05$.

of referral for mammographic examination was retrieved. Five hundred eleven lesions were included in the 'screening' group, and 339 in the 'non-screening' group. The characteristics of these patients and lesions are presented in Table 1. Reasons for women outside the national screening program to seek mammographic examination are presented in Table 2.

\section{Breast cancer prevalence}

The histological diagnosis found at SLCNB is presented in Table 3 . The prevalence of carcinoma varied significantly between the 'screening' group (64.0\%) and the 'non-screening' group (49.6\%) $(p<0.05)$. Since the threshold of participation in the national screening program in The Netherlands is 50 years of age we studied cancer prevalence for women 50 years and older separately. In the 'screening' group, all but 10 woman were 50 years or older; these 10 woman would turn 50 in the calendar year of their first screening visit. Within the 'non-screening' group, the prevalence of carcinoma was $57.2 \%$ (115/201) for women aged 50 years and older, compared to $38.4 \%$ (53/138) for the group aged $<50$ years $(p<0.01)$. Comparing only
Table 2. Reasons for women outside the national screening program to come to the clinic for mammographic evaluation

\begin{tabular}{lrr}
\hline & $n$ & $(\%)$ \\
\hline Family history of breast cancer & 121 & $(36)$ \\
Personal history of breast cancer & 101 & $(30)$ \\
Personal history of benign breast disease & 98 & $(29)$ \\
Complaints of painful breast(s) & 40 & $(12)$ \\
Skin retraction & 24 & $(7)$ \\
Nipple discharge & 19 & $(6)$ \\
Follow-up for previous malignancy other than & 6 & $(2)$ \\
$\quad$ breast cancer (e.g., ovarian cancer) & & \\
\hline
\end{tabular}

women aged 50 years or older between 'screening' and the 'non-screening' group, there was no significant difference in breast cancer prevalence (64 vs. $57 \%$, respectively).

Predictive values, sensitivity, and specificity

The predictive value of a 'normal breast tissue' diagnosis, the predictive value of a 'benign' diagnosis, 
Table 3. Histological classification on SLCNB

\begin{tabular}{lrrrrr}
\hline & \multicolumn{2}{c}{$\begin{array}{c}\text { Screening } \\
n=511\end{array}$} & \multicolumn{2}{c}{$\begin{array}{c}\text { Non-screening } \\
n=339\end{array}$} \\
\cline { 2 - 3 } \cline { 5 - 6 } & \multicolumn{1}{c}{$n$} & $(\%)$ & & \multicolumn{1}{c}{$n$} \\
\hline Normal breast tissue & 14 & $(2.7)$ & & 16 & $(4.7)$ \\
Benign disease & 164 & $(32.1)$ & & 154 & $(45.4)$ \\
High-risk lesion & 15 & $(2.9)$ & & 11 & $(3.2)$ \\
DCIS & 116 & $(22.7)$ & & 73 & $(21.5)$ \\
Invasive cancer & 202 & $(39.5)$ & & 85 & $(25.1)$ \\
Prevalence of carcinoma* & 327 & $\left(64.0^{* *}\right)$ & 168 & $(49.6)$ \\
\hline
\end{tabular}

*Final histological diagnosis after correlation with the excision biopsy.

** Significantly different between screening and non-screening with a $p<0.05$.

Table 4. Diagnostic accuracy of stereotactic large core needle biopsy

\begin{tabular}{|c|c|c|c|c|c|c|}
\hline & \multicolumn{2}{|c|}{$\begin{array}{c}\text { COBRA study* } \\
\quad N=858\end{array}$} & \multicolumn{2}{|c|}{$\begin{array}{c}\text { Screening } \\
n=511\end{array}$} & \multicolumn{2}{|c|}{$\begin{array}{c}\text { Non-screening } \\
n=339\end{array}$} \\
\hline & $\%$ & $(95 \% \mathrm{CI})$ & $\%$ & $(95 \% \mathrm{CI})$ & $\%$ & $(95 \% \mathrm{CI})$ \\
\hline Predictive value 'normal breast tissue' & 83 & $(65-94)$ & 71.4 & $(42-92)$ & 93.8 & $(70-100)$ \\
\hline Predictive value 'benign' diagnosis & 96 & $(93-98)$ & 97.0 & $(93-99)$ & 94.8 & $(90-98)$ \\
\hline ‘High-risk’ underestimate & 23 & $(9-44)$ & 26.7 & $(8-55)$ & 18.2 & $(2-52)$ \\
\hline 'DCIS' underestimate & 17 & $(12-22)$ & 14.7 & $(8-21)$ & 20.5 & $(12-32)$ \\
\hline Sensitivity large-core needle biopsy & 97 & (95-98) & 98.5 & $(97-100)$ & 95.2 & (91-98) \\
\hline Specificity large-core needle biopsy & 99 & $(97-100)$ & 97.8 & (95-99) & 99.4 & $(97-100)$ \\
\hline
\end{tabular}

the high-risk underestimate rate and the DCIS underestimate rate are presented in Table 4 . There were no significant differences in these parameters between the two groups.

On a total of 327 malignancies in the 'screening' group, five lesions would have been diagnosed as benign, and these patients would not have received adequate therapy. This resulted in a sensitivity rate of $98.5 \%(95 \%$ CI $96.5-99.5)$. In the 'nonscreening' group this was $95.2 \%$ (95\%CI 90.8-97.9) (160/168).

In the screening group, four times malignant disease (DCIS or invasive cancer, IC) was found at core biopsy, while only benign disease was found at surgical excision (4/184). For the 'non-screening group', one of 171 lesions was incorrectly diagnosed as malignant. After revision by an expert panel (consisting of three specialized breast pathologists and two specialized breast radiologists) it was concluded that the pathologist had incorrectly diagnosed these needle biopsies as malignant. These five patients would have been over-treated and hence the findings were called 'false positives'. This resulted in specificities of $97.8 \%$ (95\%CI 94.5-99.4) for the 'screening' group versus 99.4\% (95\%CI 96.8-100) for the 'non-screening' group $(p>0.05)$.

\section{Discussion}

Our current study shows that in a group of consecutive patients referred for histological examination of a mammographically detected nonpalpable lesion, as many as $40 \%$ (339/850) is referred from outside the national screening program. This is the first study comparing lesions of patients referred outside the national screening program to screen-detected lesions. Women seeking mammographic examination outside the national screening program have an increased prevalence of riskfactors for, or symptoms suggestive of breast cancer. However, prevalence of carcinoma was lower in this subgroup. A possible explanation could be that both the patient (seeking help) and her doctor (referring her for histological examination) perceive 
an increased risk, and do not want to miss breast cancer; hence referral is made at a lower degree of suspicion in comparison with asymptomatic women from the screening program. This is especially true for women $<50$ years, since the prevalence of breast cancer in older women is comparable to the results of the breast cancer screening program.

With the increasing knowledge about breast cancer, and the known positive effects of screening on morbidity and mortality, the awareness of women towards breast examination is growing, thereby inducing an increase in the number of nonpalpable lesions detected. Also, because of the detection of breast cancer susceptibility genes such as BRCA1 and 2, there may be an increase in the number of young women referred for risk assessment and counseling. At the same time, as more women survive breast cancer, they demand close surveillance, which leads to an increase of women seeking mammographic surveillance outside the national screening program.

The diagnostic accuracy of any test used is influenced by the prevalence of disease. Specifically, the risk of finding cancer despite a benign diagnosis on SLCNB increases when the prevalence of carcinoma is higher in the population under study (examined), resulting in a higher false negative rate [12]. Before applying test results to a new (sub)population, the prevalence of breast cancer should be assessed. In doing so, no differences were found for any of the main outcome parameters describing the accuracy of SLCNB.

In conclusion, stereotactic large core needle biopsy is an accurate diagnostic test for evaluating nonpalpable mammographic abnormalities both in women referred from the national screening program and in women referred outside screening. Careful monitoring of the implementation of this new diagnostic technique in The Netherlands is mandatory to ensure patients' safety.

\section{Acknowledgements}

COBRA study group (COre Biopsy after RAdiological localisation): APE Besnard, IHM Borel Rinkes, E Buskens, WAH Gelderman, AD Groote, JHCL Hendriks, R Holland, LE Hoorntje, PKH Hut, HJ de Koning, WPThM Mali, M Oudkerk, PHM Peeters, JL Peterse, RM Pijnappel, EJT Rutgers, MEI Schipper, P Schipper, JG van den Tweel, HM Verkooijen, ThJMV van Vroonhoven, PFGM van Waes, T Wiggers.

\section{References}

1. Fracheboud J, de Koning HJ, Beemsterboer PMM, Boer R, Hendriks JHCL, Verbeek ALM, van Ineveld BM, de Bruyn AE, van der Maas PJ: Nation-wide breast cancer screening in The Netherlands: results of initial and subsequent screening 1990-1995. Int J Cancer 75: 694-698, 1998

2. Kerlikowske K, Grady D, Rubin SM, Sanrock C, Ernster VL: Efficacy of screening mammography. A meta-analysis. JAMA 273(2): 149-154, 1995

3. Nyström L, Rutqvist LE, Wall S, Lindgren A, Lindqvist M, Ryden S, Andersson I, Bjurstam N, Fagerberg G, Frisell J: Breast cancer screening with mammography: overview of swedish randomised trials. Lancet 341(8851): 973-978, 1993

4. Tabàr L, Vitak B, Tony HH, Yen MF, Duffy SW, Smith RA: Beyond randomized controlled trials: organized mammographic screening substantially reduces breast cancer mortality. Cancer 91(9): 1724-1731, 2001

5. Blanks RG, Moss SM, McGahan CE, Quinn MJ, Babb PJ: Effect of NHS breast screening programme on mortality from breast cancer in England and Wales, 1990-1998: comparison of observed with predicted mortality. BMJ 321: 665-669, 2000

6. Fracheboud J, de Koning HJ, Boer R, Groenewoud JH, Verbeek ALM, Broeders MJM, van Ineveld BM, Hendriks JHCL, de Bruyn AE, Holland R, van der Maas PJ: Nationwide breast cancer screening programme fully implemented in The Netherlands. The Breast 10(1): 6-11, 2001

7. Boer R, Koning HJ de, Oortmarssen GJ van, Maas PJ van der: In search of the best upper age limit for breast cancer screening. Eur J Cancer 31A: 2040-2043, 1995

8. Parker SH, Lovin JD, Jobe WE, Luethke JM, Hopper KD, Yakes WF, Burke BJ: Stereotactic breast biopsy with a biopsy gun. Radiology 176: 741-747, 1990

9. Brenner RJ, Bassett LW, Fajardo LL, Dershaw DD, Evans WP 3rd, Hunt R, Lee C, Tocino I, Fisher P, McCombs M, Jackson VP, Feig SA, Mendelson EB, Margolin FR, Bird R, Sayre J: Stereotactic core-needle breast biopsy: a multiinstitutional prospective trial. Radiology 218(3): 866-872, 2001

10. Morrow M, Venta L, Stinson T, Bennett C: Prospective comparison of stereotactic core biopsy and surgical excision as diagnostic procedures for breast cancer patients. Ann Surg 233(4): 537-541, 2001

11. Verkooijen HM: Diagnostic accuracy of stereotactic large-core needle biopsy for nonpalpable breast disease: results of a multicenter prospective study with $95 \%$ surgical confirmation. Int J Cancer 2002, in press.

12. Verkooijen HM, Peeters PHM, Buskens E, Koot VCM, Borel Rinkes IHM, Mali WPThM, van Vroonhoven ThJMV: Diagnostic accuracy of large-core needle biopsy for nonpalpable breast disease: a meta-analysis. Br J Cancer 82(5): 1017-1021, 2000

13. Verkooijen HM, Peeters PHM, Pijnappel RM, Koot VCM, Schipper MEI, Borel Rinkes IHM: Diagnostic accuracy of needle-localized open breast biopsy for impalpable breast disease. Br J Surg 87: 344-347, 2000

14. Moons KG, van Es GA, Deckers JW, Habbema JD, Grobbee DE: Limitations of sensitivity, specificity, likelihood ratio and Bayes theorem in assessing diagnostic probabilities: a clinical example. Epidemiology 8: 12-17, 1997

15. Burbank F, Parker SH: Methods for evaluating the quality of an image guided breast biopsy program. Sem Breast Dis 1: 71-83, 1998 
16. Jackman RJ, Nowels KW, Rodriguez-Soto J, Marzoni FA, Finkelstein SD, Shephard MJ: Stereotactic, automated, large-core needle biopsy of nonpalpable breast lesions: falsenegative and histologic underestimate rates after long-term follow up. Radiology 210: 799-805, 1999

17. Liberman L, Cohen MA, Dershaw DD, Abramson AF, Hann LE, Rosen PP: Atypical ductal hyperplasia diagnosed at stereotaxic core biopsy of breast lesions. An indication for surgical biopsy. AJR 164: 1111-1113, 1995

18. Brown TA, Wall JW, Christensen ED, Smith DV, Holt CA, Carter PL, Patience TH, Babu SS, Williard WC: Atypical hyperplasia in the era of stereotactic core needle biopsy. J Surg Oncol 67: 168-173, 1998

19. Gadzala DE, Cederbom GJ, Bolton JS, McKinnon WM, Farr GH, Champaign J, Ordoyne K, Chung K, Fuhrman GM:
Appropriate management of atypical ductal hyperplasia diagnosed by stereotactic core needle breast biopsy. Ann Surg Oncol 4: 283-286, 1997

20. Latosinsky S, Cornell D, Bear HD, Karp SE, Little S, Paredes ED: Evaluation of stereotactic core needle biopsy (SCNB) of the breast at a single institution. Breast Cancer Res Treat 60(3): 277-283, 2000

Address for offprints and correspondence: WPThM Mali, Department of Radiology, University Medical Centre, E 01.132, PO Box 85500, 3508 GA Utrecht, The Netherlands; Tel.: +31-30-250 6687; Fax: +31-30-258 1098; E-mail:w.mali@azu.nl 